\title{
Parto de adolescentes: elementos qualitativos da assistência
}

\author{
DELIVERY IN ADOLESCENTS: QUALITATIVE FACTORS OF CARE
}

PARTO DE ADOLESCENTES: ELEMENTOS CUALITATIVOS DE LAATENCIÓN

\author{
Cleci de Fátima Enderle1, Nalú Pereira da Costa Kerber², Lulie Rosane Odeh Susin², \\ Bruna Goulart Gonçalves ${ }^{4}$
}

\section{RESUMO}

O estudo buscou conhecer o que as adolescentes entendem como assistência adequada ao parto. Dados coletados através de entrevista individual com as adolescentes que tiveram seu parto em um Hospital Universitário do sul do Brasil, entre julho de 2008 e outubro de 2009. Foi efetuada uma análise temática, que se baseou nas preconizações do Ministério da Saúde sobre o parto humanizado. Despontaram núcleos temáticos relacionados à necessidade de atenção, de orientação e de respeito. $A$ atenção apareceu como elemento significativo e primordial, caracterizada pela compreensão, diálogo e participação ativa no processo de parir, assinalada pelo pronto atendimento às solicitações, compreensão pelo fato de desconhecerem as rotinas e procedimentos, interação com a equipe, sem serem simplesmente visualizadas como sujeitos passivos.

\section{DESCRITORES}

Adolescente

Parto

Parto humanizado

Enfermagem obstétrica

\begin{abstract}
The objective of this study was to learn what adolescents understand as appropriate delivery care. Data were collected through individual interviews with adolescents who delivered at a University Hospital in southern Brazil, between July 2008 and October 2009. A thematic analysis was performed, based on the recommendations of the Ministry of Health regarding humanized delivery. Theme nuclei emerged related to the need for care, guidance and respect. Care appeared as a significant and primordial factor, characterized by understanding, dialogue and an active participation in the delivery process, marked by a timely attention to their needs, understanding their unfamiliarity with the routines and procedures, having a good interaction with the team and not being seen as passive subjects.
\end{abstract}

DESCRIPTORS
Adolescent
Parturition
Humanizing delivery
Obstetrical nursing

\section{RESUMEN}

El estudio buscó conocer lo que las adolescentes entienden como atención adecuada al parto. Datos recolectados a través de entrevista individual con adolescentes que tuvieron su parto en un Hospital Universitario del sur de Brasil, entre julio 2008 y octubre 2009. Fue efectuado un análisis temático, que se basó en las recomendaciones del Ministerio de Salud sobre parto humanizado. Asomaron núcleos temáticos relacionados a la necesidad de atención de orientación y de respeto. La atención apareció como elemento significativo $y$ primordial, caracterizada por la comprensión, diálogo y participación activa en el proceso de parto, señalada por la rápida atención a las solicitudes, comprensión por el hecho de desconocer las rutinas y procedimientos, interacción con el equipo, sin ser simplemente visualizadas como sujetos pasivos.

\section{DESCRIPTORES \\ Adolescente \\ Parto \\ Parto humanizado \\ Enfermería obstétrica}

\footnotetext{
${ }^{1}$ Mestre em Ciências da Saúde pela Universidade Federal do Rio Grande. Enfermeira do Hospital Universitário Dr. Miguel Riet Corrêa Jr. Integrante do Grupo de Pesquisa Viver Mulher do Programa de Pós-Graduação em Enfermagem da Universidade Federal do Rio Grande. Rio Grande, RS, Brasil. clecienderle@gmail.com.br ${ }^{2}$ Enfermeira. Doutora em Enfermagem. Docente da Escola de Enfermagem e Programa de Pós-Graduação em Enfermagem da Universidade Federal do Rio Grande. Líder do Grupo de Pesquisa Viver Mulher. Rio Grande, RS, Brasil. nalu@vetorial.net ${ }^{3}$ Médica. Doutora em Ciências Médicas pela Universidade Federal do Rio Grande do Sul. Docente da Faculdade de Medicina da Universidade Federal do Rio Grande e do Curso de Mestrado em Ciências da Saúde. Integrante do Grupo de Pesquisa Viver Mulher do Programa de Pós-Graduação em Enfermagem da Universidade Federal do Rio Grande. Rio Grande, RS, Brasil. susin@mikrus.com.br ${ }^{4}$ Mestranda do Programa de Pós-Graduação em Enfermagem da Universidade Federal do Rio Grande. Bolsista CAPES. Enfermeira do Hospital Santa Casa. Integrante do Grupo de Pesquisa Viver Mulher do Programa de Pós-Graduação em Enfermagem da Enfermagem da Universidade Federal do Rio Grande. Rio Grande, RS, Brasil. brunaggonçalves@gmail.com
} 


\section{INTRODUÇÃO}

O Ministério da Saúde (MS), no Programa de Saúde do Adolescente (PROSAD), conceitua adolescência como um período de vida, caracterizado por crescimento e desenvolvimento, manifestando-se por mudanças anatômicas, fisiológicas e psicossociais, delimitado pela faixa etária compreendida entre 10 e 19 anos. Adotar um critério cronológico objetiva a identificação de requisitos que orientem a investigação epidemiológica, na elaboração de estratégias de políticas de desenvolvimento coletivo e na programação de serviços sociais e de saúde pública ${ }^{(1)}$.

Com a iniciação sexual cada vez mais precoce e, não raro, sob condições sociais bastante desfavoráveis, a sexualidade vivenciada, muitas vezes é acompanhada de uma gravidez. São muitas as causas relacionadas à frequência da gravidez na adolescência, despontando como as mais discutidas na literatura: maturação sexual precoce; início da vida sexual mais cedo; pouco conhecimento do uso de métodos contraceptivos; retardo da idade ao casamento; fragilidade da tutela familiar; e processo acelerado de urbanização, com mudança significativa no estilo de vida(2).

Um grande número de adolescentes tem vivenciado um processo gestacional, o que pode ser visualizado por meio dos dados referidos pelo MS do ano de 2005, em que $21,8 \%$ dos partos realizados no Sistema Único de Saúde (SUS) foram de adolescentes na faixa etária de 10 a 19 anos $^{(1)}$, e a taxa de fecundidade adolescente, em 2006, cresceu em 0,14 nas classes econômicas mais baixas $^{(3)}$. Focalizando o município do Rio Grande, dados de 2007 mostram a ocorrência de 2.584 nascimentos por parto hospitalar, sendo que 506 destes partos (19,9\%) foram de mulheres com menos de 20 anos. A média se manteve em 2008, com o número de 2.506 nascimentos, sendo $20,2 \%$ (516) de mulheres com idade entre 10 e 19 anos $^{(4)}$.

A partir destas considerações, percebe-se a importância de serem estabelecidas políticas públicas direcionadas para essa clientela, no intuito de proporcionar uma assistência contextualizada, de qualidade e baseada nos princípios da humanização da atenção.

Buscando uma assistência mais humanizada no atendimento obstétrico e neonatal, o Ministério da Saúde (MS), no ano de 2000, instituiu o Programa de Humanização no Pré-Natal e Nascimento (PHPN), cujo objetivo foi assegurar a melhoria do acesso da cobertura e da qualidade do acompanhamento pré-natal, da assistência ao parto e puerpério. $O$ enfoque principal desse documento é a mulher e o resgate da dignidade durante o processo parturitivo, buscando consolidar a transformação da atenção prestada durante a gestação, o parto e o puerpério ${ }^{(5)}$.
A implantação do PHPN pode ser considerada um marco, um divisor de águas, pois permitiu o diálogo sobre a mudança de condutas e de procedimentos adotados nos serviços, uma vez que o programa prioriza o parto vaginal, a não medicalização do parto e a redução de intervenções cirúrgicas. O programa adota uma postura crítica em relação aos procedimentos que levam à despersonalização da mulher, e à realização de cesáreas desnecessárias, porém, incentiva o processo de parto ativo como um acontecimento fisiológico(6).

Apesar de o PHPN ser uma política de atenção que se mostra promissora no sentido de qualificação da assistência ao pré-natal e parto, não considera as especificidades da parturiente adolescente. Ao buscar estudos desenvolvidos diretamente com esta clientela, percebe-se uma lacuna, uma vez que não são muitos os autores que discutem essa questão.

Um dos estudos encontrados, que tentou compreender o significado do parto humanizado para as adolescentes, evidenciou o quão importante é agir com respeito e dignidade para com o outro(7). Salienta o papel da equipe nesse processo, inclusive na busca pela diminuição de normas e rotinas que, segundo os autores, são encontradas em demasia nas instituições de saúde.

Em outra investigação, que teve como objetivo compreender a vivência da adolescente primípara frente ao parto, os depoimentos demonstram que o ambiente estranho das salas de pré-parto e parto intensifica os sentimentos de solidão e o medo da dor ${ }^{(8)}$. Argumentam que há um distanciamento entre o profissional e a adolescente, no sentido de compreender o significado desse tipo de vivência, valorizando aspectos técnicos em detrimento da relação com o sujeito.

Levando-se em conta as peculiaridades inerentes a esta categoria, somadas à realidade encontrada no município do Rio Grande, para que as adolescentes possam vivenciar uma maternidade segura, tendo seus direitos assegurados por políticas de saúde, é que se busca, neste estudo, conhecer o que as adolescentes entendem por adequada assistência ao parto.

\section{MÉTODO}

O presente estudo é um recorte do banco de dados da macropesquisa multicêntrica, envolvendo a Universidade Federal do Rio Grande (FURG), a Universidade Federal de Pelotas (UFPEL) e a Faculdade Santa Clara, de Santa Maria (FASCLA). A macropesquisa apresenta abordagem quanti-qualitativa e investiga a assistência ao parto de adolescentes nos Hospitais Universitários (HU) destas instituições, com coleta de dados realizada de julho de 2008 a outubro de 2009. 
O banco de dados é composto das entrevistas semiestruturadas, realizadas com as adolescentes que foram assistidas em trabalho de parto no Centro Obstétrico (CO), pelo Sistema Único de Saúde (SUS), com os familiares ou acompanhantes que se encontravam presentes aguardando o término do processo de nascimento, com os trabaIhadores da saúde atuantes nos COs, com os gestores e, também, dos dados coletados por intermédio da pesquisa nos prontuários das adolescentes assistidas. Salienta-se que foram excluídas as adolescentes que, na finalização do trabalho de parto, originaram fetos mortos, de modo a preservar sua integridade emocional.

O presente estudo faz uma abordagem qualitativa e utiliza unicamente os dados coletados a partir das entrevistas com as adolescentes que tiveram seus partos realizados no $\mathrm{CO}$, do $\mathrm{HU}$, da Universidade Federal do Rio Grande, em um total de 269 entrevistas. Foi efetuada a leitura de todas as entrevistas que compunham o banco de dados, e buscada a regularidade das respostas, de forma a reproduzir o mais fielmente possível a população de adolescentes grávidas, frente à problemática abordada. Em vista do significativo número de sujeitos, optou-se por apresentar, também, a frequência das respostas, de modo a que o leitor possa ter uma visão da expressividade dos depoimentos.

Foi utilizada a seguinte questão do instrumento de pesquisa: $O$ que você considera como uma assistência ideal, de qualidade, para os momentos que uma gestante permanece no CO? Entende-se que, a partir do relato das mulheres, sujeitos do cuidado, sobre a forma como gostariam de ser tratadas nesse espaço assistencial, é possível refletir sobre a concepção que as mesmas apresentam acerca de humanização do parto.

A macropesquisa, à qual o presente estudo está vinculado, obteve a aprovação do Comitê de Ética em Pesquisa (CEPAS), da Universidade Federal do Rio Grande sob o número 31/2008. A adolescente e seu responsável legal foram devidamente esclarecidos sobre a pesquisa, que teriam seus nomes preservados e poderiam desistir a qualquer momento da participação. Após, assinaram o Termo de Consentimento Livre e Esclarecido.

Para o tratamento dos dados foi utilizada a análise temática, seguindo as etapas sugeridas de leitura repetitiva, organização e ordenação dos dados, de forma a buscar as regularidades em que se apresentaram os achados ${ }^{(9)}$. Como forma de facilitar a visualização destes achados, os dados que apresentaram maior número de repetição foram organizados em categorias e, posteriormente, agrupados por similaridade, nos seguintes núcleos temáticos: necessidade de atenção, necessidade de orientação e necessidade de respeito. Assim, a análise processou-se de acordo com as determinações preconizadas pelo MS e descritas no PHPN, que enfatiza a afirmação dos direitos da mulher, propondo a humanização como estratégia para a melhoria da qualidade da atenção.

\section{RESULTADOS}

Antes de iniciar a apresentação dos núcleos temáticos elencados, optou-se por dar visibilidade às categorias que se sobressaíram por meio da leitura dos depoimentos, as quais estão dispostas na Tabela 1.

Tabela 1 - Relação das categorias de qualidade na assistência ao parto

\begin{tabular}{llcc}
\hline \multicolumn{1}{c}{$\begin{array}{c}\text { Núcleo } \\
\text { Temático }\end{array}$} & Categorias & Nr. Absoluto & Nr. Percentual \\
\hline \multirow{2}{*}{$\begin{array}{l}\text { Necessidade } \\
\text { de atenção }\end{array}$} & Acomção & 71 & $26,4 \%$ \\
& Ter alguém por & 12 & $12,6 \%$ \\
& perto & & $4,5 \%$ \\
\hline \multirow{2}{*}{ Necessidade } & Orientação & 30 & \\
de orientação & Informação aos & 12 & $4,5 \%$ \\
& familiares & & \\
\hline \multirow{2}{*}{ Necessidade } & Paciência & 25 & $9,2 \%$ \\
de Respeito & Privacidade & 22 & $8,2 \%$ \\
& Pedir opinião & 12 & $4,0 \%$ \\
\hline
\end{tabular}

Fonte: Entrevistas semi-estruturadas com adolescentes atendidas no CO do Hospital Universitário - Rio Grande, Rio Grande do Sul - julho de 2008 a outubro de 2009

Aproximando-se as categorias por similaridade, despontam os núcleos temáticos já referidos anteriormente, que se conformaram de modo a mostrar as necessidades de assistência vislumbradas nos depoimentos das adolescentes. Para qualificar os resultados apresentados, foram transcritas algumas falas consideradas ilustrativas de cada um dos aspectos considerados.

\section{Necessidade de Atenção}

Neste núcleo estão presentes as necessidades de atenção e da presença de um acompanhante ou alguém por perto. Como podemos observar na Tabela 1, a maioria das adolescentes $(26,4 \%)$ relatou ser a atenção o item de maior importância para o atendimento no momento do parto.

Ah, eles tem que dar atenção, porque, às vezes, a gente pede e eles não vêm (AF032).

(...) entender que a gente está com medo e dar atenção (AF123).

Atenção, acalmar, pois é um momento difícil (AF221).

A presença de um acompanhante durante o processo de parturição foi citada por quase $13 \%$ das adolescentes como um aspecto importante da assistência, o que as deixaria mais seguras, sentindo-se apoiadas física e emocionalmente.

Ah! No caso eu acho que tinham que deixar a minha mãe entrar, tinha que deixar. Tinha que ter um acompanhante (AF004).

(...) teria que ter um acompanhante, familiar, ainda mais porque tu és menor de idade (AF018). 
Ah! Eu acho que poderia ficar alguém ali da família acompanhando, porque a pessoa vai para lá, fica com dor, acho que só isso que ali tem problema (AF033).

Outras entrevistadas relataram a importância de ter alguém por perto $(4,5 \%)$, segurar a mão, estar presente, poder conversar, de forma a não sentirem-se sós. Podemos observar tal fato nas falas a seguir:

O que eu achei bom ali, é que tinha sempre alguém por perto, tinha uma enfermeira que dizia que era assim mesmo, aí eu me acalmei um pouco, não fiquei tão insegura (AF011).

De preferência um enfermeiro do lado seria bom, não sei por que, mas seria bom (...) (AF040).

Ter alguém para ficar do lado da gente e explicar o que está acontecendo (AF103).

\section{Necessidade de Orientação}

Observa-se, através dos depoimentos, a clara necessidade das parturientes de sentirem-se incluídas no cuidado, partícipes desse processo. No Quadro 1, percebe-se que $15,5 \%$ fez uma ligação entre a assistência ideal e o direito à informação e orientação.

\begin{abstract}
O ideal era eles te explicarem mais, conversarem mais a respeito. Eles te deixam ali, vão fazer as coisas e tu ficas ali sem saber o que tu está esperando. Acho que eles têm que explicar mais: Agora tu vai ficar aqui, depois tu vai para lá..., para não te deixar ansiosa (AF060).
\end{abstract}

Deveria alguém estar sempre te dando informações, quando me examinassem me dar informação, do tipo: estás com dilatação, sem dilatação, mais diálogo (AF069).

Acho que explicar como tu está, te deixarem informada (AF194).

A informação solicitada diz respeito, também, aos familiares que estão esperando por notícias. A incerteza das parturientes, de que seus familiares irão receber notícias da evolução do trabalho de parto, do quanto falta para o nascimento, se o parto vai ser normal ou cesariana, faz com que aumente a ansiedade, pois como se encontram separadas de seus familiares, querem que eles saibam o que está acontecendo, sentindo-se assim mais amparadas e seguras.

Em relação aos meus familiares, eles deveriam dar mais atenção para eles, por que eles estão nervosos na rua (...). Eles podiam pelo menos ir ali na porta e dar notícias para eles de vez em quando, assim eles não ficariam batendo toda hora na porta (AF027).

(...) não deixar os familiares sem notícia (AF234).

\section{Necessidade de Respeito}

Para melhor traduzir as opiniões das adolescentes neste núcleo temático, foram englobadas, aqui, as categorias de paciência, respeito, pedir opinião e privacidade, totalizando $23,2 \%$ das entrevistadas.
Ter paciência aparece nas falas traçando um paralelo com o medo do desconhecido, e o despreparo diante do parto eminente. A dor do parto aparece como algo muito forte, de difícil superação. Esperam mais carinho e compreensão frente ao seu despreparo e as muitas dúvidas perante a evolução do trabalho de parto.

Que eles tivessem um pouco mais de paciência com a gente, que respondessem o que a gente pergunta. $O$ médico mesmo, eu falava que estava com dor, que não aguentava mais (...) e ele estava deitado na cama, olhando TV (...) nem pra dizer: te acalma guriazinha (...) (F013).

Passar tranquilidade e serem mais compreensíveis (...) (AF065).

As pessoas não ficarem gritando com a gente. Ter calma, ter paciência (AF 122).

Quando citaram o respeito dos membros da equipe, os sujeitos mostram que, em sua experiência como parturiente, isso não foi levado em consideração, como pode ser observado através dos depoimentos. A seguir, as adolescentes foram inclusive maltratadas, num momento tão delicado e importante de suas vidas.

Ideal seria se eles tivessem me tratado com mais respeito, com certeza teria sido melhor (...) (AF006).

(...) fora as grosserias do médico estava tudo bem, só podia melhorar a educação do médico (AF039).

Tratar bem e não xingar ( AF119)

As parturientes reforçam o fato de não serem consultadas quanto aos procedimentos que a equipe vai tomar em relação ao seu corpo e, tampouco, solicitar sua opinião e colaboração no processo de parir.

\section{(...) Se tivessem pedido minha opinião, eles faziam o que queriam e não pediam a opinião (AF006).}

(...) sou mãe de primeira viagem e eles não me informaram nada, o que iam fazer comigo; só me disseram que eu tinha que fazer força, mas eu não sentia contração, não sentia nem dor (AF018).

(...) eles não explicam nada para a gente; achei até que ia morrer porque me levaram para a cesárea e só disseram que não dava para ser normal. Eu nem sabia o que estava acontecendo. Deveriam dar mais explicação (AF257).

Em relação à privacidade, poucas foram as adolescentes que citaram essa questão como muito importante no momento do parto. Porém, as que se manifestaram, o fizeram com firmeza, sentindo-se incomodadas quando esta não foi respeitada.

(...) menos pessoas na sala de parto, eu não sei, acho que tinha umas oito pessoas lá dentro, e depois mandaram chamar outra médica (AF018).

Nem sei, porque foi a primeira vez (...), só tinha muita gente (AF056). 
Finalizando a apresentação dos resultados, é necessário comentar que, durante as entrevistas, algumas adolescentes (17\%) preferiram não expressar sua opinião sobre o que consideram uma assistência ideal, de qualidade, nos momentos em que estiveram no centro obstétrico. Algumas disseram que o modo como foram atendidas foi adequado, não sabendo o que dizer a respeito. Essa parcela, então, não conseguiu contribuir para o objetivo da investigação.

\section{DISCUSSÃO}

Como é possível observar pelas entrevistas, o aspecto que sobressai nos depoimentos é o déficit de atenção na assistência ao parto. Essa necessidade foi percebida pelas clientes quando, ao chamar pelos profissionais que prestavam atendimento no $\mathrm{CO}$, não foram atendidas de imediato. De outra forma, é demonstrado que a equipe encara as dores como naturais, posicionando-se como se nada pudesse ser feito para amenizá-las. Neste sentido, as mulheres manifestam que só lhes restava esperar o bebê nascer para ter amenizado o sofrimento por que estavam passando.

Quando a dor se intensifica, a sensação percebida pelas adolescentes é de que o bebê já vai nascer, e se sentem sozinhas, uma vez que os profissionais estão envolvidos em outras tarefas e só agem como expectadores do trabalho de parto. Parece que os profissionais não percebem que esse tipo de situação, rotineira para eles no cotidiano desse ambiente de trabalho, não é rotineira para essas jovens mulheres, que se veem assustadas diante do momento vivido. As relações interpessoais no acompanhamento ao parto mostram-se capazes de reduzir o estresse materno, equiparando-se a recursos médicos e farmacológicos prescritos ${ }^{(10)}$.

Entende-se, pelos depoimentos, que o desejo dessas parturientes adolescentes é de, simplesmente, ter alguém para segurar sua mão, tranquilizá-las, transmitir segurança e conforto. É extremamente importante o profissional estar ao lado, junto, individualizando o atendimento ${ }^{(11)}$.

A atenção recebida pelos profissionais foi destacada em um dos estudos, como referência de qualidade no atendimento, por quase a totalidade dos relatos feitos pelas parturientes ${ }^{(10)}$. Do mesmo modo o fato de terem sido acompanhadas continuamente por alguém foi referenciado como o diferencial do atendimento.

Faz-se necessário, também, discutir a reação dos profissionais de saúde frente ao descontrole da mulher diante da dor, com atitudes repreensivas, ou adquirindo uma postura impessoal, e determinada por condutas e comportamentos pré-estabelecidos, e por práticas comprovadamente prejudiciais. A demora em adotar medidas que minimizem a dor e o desconforto no pré-parto e parto se mostra estar associada à qualidade das relações interpes- soais com os profissionais da assistência ${ }^{(8,12)}$. Na verdade, existe um conjunto de fatores que intensifica a necessidade de atenção referida pelas adolescentes: ambiente estranho; pessoas estranhas; muita dor; observação de outras mulheres em trabalho de parto, algumas expressando sua dor e angústia por meio de gritos, favorecendo assim o aparecimento do medo.

Nesse sentido, desponta outro aspecto considerado como imprescindível para garantir a qualidade da assistência: a presença de um acompanhante. Este é visualizado, como sendo a pessoa que, estando sempre presente ao seu lado, poderia lhe fornecer apoio, calma e incentivo durante o trabalho de parto. As adolescentes entendem que, dessa forma, não se sentiriam sozinhas, e isso poderia amenizar a sensação de medo de estar em um ambiente estranho e desconhecido. A presença do acompanhante de escolha da paciente é um direito previsto em lei ${ }^{(13)}$, garantido a todas as mulheres. Em se tratando de gestantes adolescentes, no Estatuto da Criança e do Adolescente (ECA), a lei assegura a presença do acompanhante, identificado como seu representante legal, durante toda a assistência(14).

Quanto à presença de acompanhante, alguns estudos $^{(11,15)}$ discutem a resistência inicial da equipe em aceitar a presença do mesmo. Entre os vários motivos alegados pelos profissionais, aparecem aspectos emocionais e sociais ligados ao acompanhante e às condições da paciente, sem despontar nenhum problema ocasionado pelas limitações funcionais ou estruturais da instituição, o que demonstra o despreparo dos profissionais da equipe.

Entende-se que uma mulher em trabalho de parto deveria estar acompanhada de pessoas de sua confiança, com as quais se sentisse confortável e segura, como o companheiro, a mãe, a melhor amiga ou uma doula. Salienta-se que o CO da instituição em que foi desenvolvido este estudo apresenta uma área física pequena, com uma sala de pré-parto coletiva, que tem apenas cortinas como recurso para preservar a privacidade das parturientes. Esse pode ser um fator dificultador para a garantia do direito ao acompanhante.

A presença do acompanhante na sala de parto ultrapassa as barreiras físicas, e o profissional de saúde precisa estar ciente de seu papel, estar capacitado e apto para se relacionar com esse novo cliente, o que demanda rever conceitos $^{(16)}$.

Logo a seguir, despontou, nos depoimentos das adolescentes, a necessidade de informação/orientação, para elas sentirem-se incluídas no cuidado, serem partícipes do processo, e não meras coadjuvantes. A interação estabelecida na relação com os profissionais tem grande influência com a satisfação do parto. A equipe tem papel importante na ajuda em reduzir o medo e a ansiedade, promovendo a tranquilidade necessária e permitindo a emoção do nascimento(15). 
Outro papel dos integrantes da equipe de saúde, de extrema relevância, é a instrumentalização das parturientes por meio da informação, que proporciona a condição para que a mulher possa fazer opções, tenha a liberdade de escolher ou recusar um procedimento relacionado a seu corpo, sendo essa escolha pertinente e convergente ao seu bem-estar. $O$ direito de decidir e opinar adequadamente deixa de existir se a informação não for fornecida ou não tiver qualidade ${ }^{(17)}$.

A necessidade de informações e esclarecimentos é extensiva aos familiares, que estão esperando por notícias, e como não as recebem, isso gera muito desconforto, incerteza e insegurança nas gestantes adolescentes. Entende-se que, nos casos em que realmente não exista a possibilidade de assegurar a presença de um acompanhante, como no caso de problemas estruturais do serviço, os profissionais deveriam manter um canal contínuo de comunicação com os familiares, garantindo informações acerca do processo assistencial que se desenrola no interior do CO.

As adolescentes em trabalho de parto estão fragilizadas, precisam ser acolhidas com calma e compreensão. Em seus depoimentos, relatam a necessidade de que a equipe tenha mais paciência, e que respeite o tempo de cada adolescente frente à dor das contrações. Muitos profissionais não conseguem compreender o despreparo com que essas mulheres chegam para ter seus filhos e perdem a paciência quando não correspondem e não colaboram com o que é proposto, ou seja, rotinas e protocolos. Tratar bem e atender as necessidades da puérpera, por meio da comunicação e da interatividade, são os principais aspectos da humanização ${ }^{(18)}$.

Em relação à necessidade de respeito e privacidade, que foi considerado como um aspecto importante, por ocasionar desconforto e insegurança quando não é observado pela equipe, é interessante contextualizar o local da pesquisa onde foram realizadas as entrevistas, o qual é um Hospital Universitário, apresentando a presença contínua de acadêmicos que se encontram em seu processo de ensino-aprendizagem, o que torna esse aspecto da privacidade mais aparente. Outro aspecto referente à necessidade de respeito está posta na tomada de decisão, em que as parturientes são mantidas à mercê desse processo, e que, segundo elas, o compartilhamento de decisões e a valorização de sua opinião caracterizam-se como imprescindíveis no sentido de assegurar uma assistência qualificada e satisfatória.

Respeitar envolve, também, ouvir o que o outro tem a dizer, respeitar suas crenças e valores, considerando os princípios da bioética da beneficência e não maleficência ${ }^{(19)}$. Os princípios bioéticos auxiliam e orientam as ações, no cuidado e na assistência, fazendo com que o respeito ao paciente ocorra de maneira mais natural ${ }^{(20)}$. Agir com respeito é agir de forma humanizada, percebendo o ser humano como um agente biopsicossocial e espiritual.
Nos discursos dos profissionais, geralmente, é ressaltado que a ajuda da mulher no parto é bem vinda, porém, na realidade, eles agem como se elas permanecessem reféns da técnica por serem dependentes da assistência ${ }^{(6)}$. A autora refere, ainda, que a visão dos profissionais é de que as mulheres podem ajudar sem interferir ou opinar; assim, silenciam-nas, e as mantêm isoladas e não participativas.

O bom relacionamento entre a gestante adolescente e os profissionais da equipe é fundamental para o processo de humanização, caracterizado por comunicação, empatia, conhecimentos e respeito pelo outro(17).

A mulher precisa ser acolhida com respeito, dando-lhe condições de fazer perguntas, e obter as respostas. Precisa ser reconhecida como alguém que possui vontade e opinião próprias, e pode compartilhar com os profissionais suas alegrias, medos e incertezas da gestação. O parto humanizado deve ser visto como um evento cheio de significados para a mulher, sua família e para o profissional que a assiste, e não como um procedimento médico ${ }^{(21)}$.

O processo de humanização e as mudanças ocorridas na assistência ao parto, só foram possíveis devido à imposição de políticas públicas. Acredita-se que, para o sucesso dessas ações, é necessária uma mudança de paradigmas, em que a mulher seja a protagonista do processo ${ }^{(22)}$ e, para alcançar essa meta, parece que ainda há um longo caminho a percorrer.

Finalmente, reflete-se na questão das adolescentes que optaram por não se manifestar, não expor sua opinião, em que se pensa em alguns fatores explicativos para tal postura, entre eles o seu estado emocional, o estresse do momento, a fragilidade inerente a pouca idade. Refletese que um motivador dessa dificuldade de resposta possa estar ligado a um possível constrangimento por parte da adolescente, de efetuar colocações acerca da assistência enquanto ainda estava internada no hospital. A pesquisa de satisfação de usuários, quando realizada ainda na instituição onde ocorre a assistência, deve ser considerada quanto ao viés por fatores como o medo frente a equipe, ou superestimação pelo desenlace feliz ${ }^{(15)}$. Por outro lado, convém lembrar que a proximidade com o momento da assistência é favorável aos detalhes. Então, entende-se que foi possível obter uma visão a partir do relato das demais participantes da pesquisa, através da diversidade de elementos de análise trazidos por elas.

\section{CONCLUSÃO}

Entende-se que as adolescentes, fragilizadas pela situação de hospitalização para o parto, não tiveram uma boa acolhida, com paciência, atenção e carinho, não receberam as mínimas informações e não se sentiram respeitadas como sujeito de direitos. Entende-se que, desta forma, a evolução do trabalho de parto torna-se difícil para todos os envolvidos, pois a sua colaboração é de suma importância no desfecho do nascimento. 
A maioria das adolescentes referiu que a atenção é elemento significativo e primordial de uma assistência ideal, caracterizada pelo pronto atendimento às solicitações, compreensão pelo fato de desconhecerem as rotinas e procedimentos, interação com a equipe, conversando, participando, contribuindo com o processo de parir, e não simplesmente sendo sujeitos passivos nesse momento.

Entende-se que, ao se falar na humanização do nascimento, é preciso proporcionar para a mulher o controle de seu corpo, deixar a natureza fisiológica agir, acompanhar o nascimento com a menor intervenção possível, porém, fornecendo apoio, orientações, informações constantes e sendo presença junto a essas mulheres sempre. Permitir que elas atuem como protagonistas do nascimento de seus filhos, pois mesmo no caso das mulheres adolescentes, inexperientes, percebe-se que há o desejo de participar ativamente de seus partos.

Pode-se concluir que a atenção desejada pelas adolescentes é aquela em que a assistência ao parto está focada, também, na individualidade de cada parturiente. Que se acredite no potencial de cada mulher de conduzir o trabaIho de parto com a orientação adequada, com paciência, carinho, atenção e compreensão. Assim, a assistência pode ser menos voltada ao cumprimento de normas e rotinas, e alicerçada nas necessidades individuais de cada adolescente, respeitando as especificidades e características delas.

\section{REFERÊNCIAS}

1. Brasil. Ministério da Saúde; Secretaria de Atenção à Saúde; Departamento de Ações Programáticas Estratégicas. Pré-natal e puerpério: atenção qualificada e humanizada [Internet]. Brasília; 2005 [citado 2010 nov. 12]. Disponível em: http://dtr2001. saude.gov.br/editora/produtos/livros/pdf/05_0151_M.pdf

2. Federação Brasileira das Associações de Ginecologia e Obstetrícia (FEBRASCO). Gravidez na adolescência: manual de orientação. São Paulo; 2009.

3. Instituto Brasileiro de Geografia e Estatística (IBGE). Síntese de indicadores sociais [Internet]. Rio de Janeiro; 2010 [citado 2010 dez. 12]. Disponível em: http://www.ibge.gov.br/home/ estatistica/populacao/condicaodevida/indicadoresminimos/ sinteseindicsociais2010/default.shtm

4. Rio Grande do Sul. Secretaria da Saúde; Núcleo de Informações em Saúde. Estatísticas de nascimento [Internet]. Porto Alegre; 2007 [citado 2010 nov. 12]. Disponível em: http://www.saude. rs.gov.br/wsa/portal/index.jsp? menu=organograma\&cod =746

5. Brasil. Ministério da Saúde. Portaria GM/MS n. 569, de 10 de junho de 2000. Institui o Programa de Humanização no Pré-Natal e Nascimento no âmbito do Sistema Único de Saúde [Internet]. Brasília; 2000 [citado 2010 nov. 13]. Disponível em: http://www.saude.mg.gov.br/atos_normativos/legislacao-sanitaria/estabelecimentos-de-saude/atendimento-humanizado/Portaria_569.pdf
Através deste estudo foi possível conhecer o que as adolescentes atendidas no hospital, entendem que seja uma assistência ideal ao parto, ou seja, desejam atenção, orientação e respeito. De posse destas informações, é possível identificar as fragilidades do serviço frente ao preconizado pelo MS para a humanização do parto, e entende-se que é preciso mobilizar toda a equipe da saúde para que conheça os resultados do estudo e possa interferir positivamente nas mudanças que se fazem necessárias, para que se consiga implementar essa política efetivamente nesse contexto.

Entende-se que a implantação de políticas e programas ministeriais voltados para a melhoria da qualidade e humanização do parto e nascimento vem crescendo no país, e os estudos sobre o tema têm se intensificado. $O$ que demonstra o interesse e a importância desta temática, embora a maioria retrate a humanização do parto de forma abrangente, não voltada especificamente para a adolescente.

As pesquisas sobre humanização do parto têm contribuído muito para a reflexão e a crítica do modelo atual de assistência, tecnocrático, curativo e especializado. Propõem mudanças no paradigma técnico-científico em saúde e na formação profissional, possibilitando rever posturas frente aos direitos humanos e nas relações de poder entre o profissional e o cliente.

6. Griboski RA, Guilbem D. Mulheres e profissionais de saúde: imaginário cultural na humanização ao parto e nascimento. Texto Contexto Enferm. 2006;15(1):107-14.

7. Oliveira ZMLP, Madeira AMF. Vivenciando o parto humanizado: um estudo fenomenológico sob a ótica de adolescentes. Rev Esc Enferm USP. 2002;36(2):133-40.

8. Silva MO, Lopes RLM, Diniz NMF. Vivência do parto normal em adolescentes. Rev Bras Enferm. 2004;57(5):596-600.

9. Minayo MC. O desafio do conhecimento: pesquisa qualitativa em saúde. 10ae ed. São Paulo: Hucitec; 2007.

10. Rodrigues AV, Siqueira AAF. Sobre as dores e temores do parto: dimensões de uma escuta. Rev Bras Saúde Matern Infant. 2008;8(2):179-86.

11. Nagahama EEI, Santiago SM. Práticas de atenção ao parto e os desafios para humanização do cuidado em dois hospitais vinculados ao sistema único de saúde em município da região Sul do Brasil. Cad Saúde Pública. 2008;24(8):1859-68.

12. Almeida CAL, Tanaka OY. Perspectiva das mulheres na avaliação do Programa de Humanização do Pré-Natal e Nascimento. Rev Saúde Pública. 2009;43(1):98-104. 
13. Brasil. Lei n. 11.108 , de 7 de abril de 2005. Altera a Lei no 8.080, de 19 de setembro de 1990, para garantir as parturientes o direito a presença de acompanhante durante o trabalho de parto e pós-parto imediato, no âmbito do Sistema Único de Saúde - SUS [Internet]. Brasília; 2005 [citado 2010 nov. 13]. Disponível em: http://www.planalto.gov.br/ ccivil_03/_Ato2004-2006/2005/Lei/L11108.htm

14. Brasil. Lei n. 8.069, de 13 de julho de 1990. Dispõe sobre o Estatuto da Criança e do Adolescente e dá outras providências [Internet]. Lei Brasília; 1990 [citado 2010 out. 14]. Disponível em: http://www.planalto.gov.br/ccivil_03/leis/ L8069.htm

15. Queiroz MVO, Jorge MSB, Marques JF, Cavalcante AM, Moreira KAP. Indicadores de qualidade da assistência ao nascimento baseados na satisfação de puérperas. Texto Contexto Enferm. 2007;16(3):479-87.

16. Longo C, Andraus L, Barbosa M. Participação do acompanhante na humanização do parto e sua relação com a equipe de saúde. Rev Eletr Enferm [Internet]. 2010 [citado 2010 set. 23]; 12(2):386-91. Disponível em: www.revistas.ufg.br/ index.php/fen/article/view/5266/6945
17. Machado NXS, Praça NS. Centro de Parto Normal e Assistência Obstétrica centrada nas necessidades da parturiente. Rev Esc Enferm USP. 2006;40(2):274-9.

18. Queiroz MVO, Silva AO, Jorge MSB. Cuidado de enfermagem à puérpera em uma unidade de internação obstétrica: perspectivas de humanização. Rev Baiana Enferm. 2003;18(1/2): 29-37.

19. Anjos MF. Dignidade humana em debate. Bioética. 2004;12(1):109-14.

20. Barbosa IA, Silva MJP. Cuidado humanizado de enfermagem: o agir com respeito em um hospital universitário. Rev Bras Enferm. 2007;60(5):546-51.

21. Dias MAB, Deslandes SF. Expectativas sobre a assistência ao parto de mulheres usuárias de uma maternidade pública do Rio de Janeiro, Brasil: os desafios de uma política pública de humanização da assistência. Cad Saúde Pública. 2006;22(12):2647-55.

22. Castro JC, Clapis MJ. Parto humanizado na percepção das enfermeiras obstétricas envolvidas com a assistência ao parto. Rev Latino Am Enferm. 2005;13(6):960-7. 